\title{
Dealing with the wicked issue of child poverty: Inter-organizational networks as forums for collective debate and reflection
}

Nicolas Jacquet, Dorien Van Haute, Joris De Corte, Laurent Nisen, Michel Vandenbroeck \& Griet Roets

\begin{abstract}
In the international realm, inter-organizational networking is perceived as a highly relevant instrument in social policy that enables welfare organizations to deal with 'wicked issues'. In this article, we discuss the central empirical findings acquired from a recent qualitative research project that focuses on interorganizational networks that were formed at the local level to deal with the wicked issue of child poverty as a complex and multidimensional social problem. We explore how the network discussions about normative value orientations in four inter-organizational networks evolve, and identify three central fields of tension that illustrate the complexity for local welfare actors in and across networks to create network strategies in dealing with child poverty: (1) selective versus universal provision, (2) conditional versus unconditional strategies, and (3) instrumental versus life-world oriented approaches. Our findings show that networks can function as valuable forums for collective debate and reflection, since different approaches and perspectives to tackle the problem of (child) poverty can be confronted with each other. Creating such a forum has the potential to challenge dominant conceptualizations and undesirable assumptions of complex social problems that are present in welfare practices and policies.
\end{abstract}

\section{Keywords}

Inter-organizational networks, (child) poverty, social policy, welfare provision 


\section{Introduction}

Governments have recently faced major challenges in resolving highly complex and hard to manage social problems such as unemployment, homelessness, social dislocation, and child abuse and child poverty (Keast, Mandell, Brown and Woolcock 2004; Devaney and Spratt 2009). Rittel and Webber (1973) identify these problems as so-called 'wicked issues' for social policy makers. This is because issues basically cut across a diversity of service areas and policy domains and are too complex to be dealt with by single welfare organizations. Furthermore, as these problems are characterized by a high degree of complexity and uncertainty about the means-end relations, different welfare actors will inevitably pursue differing goals, propose alternative strategies and rely upon varying values to be achieved (Weber and Khademian 2008; Ferlie et al. 2011; Alford and Head 2017).

In that vein, the development of an inter-organizational or joined-up approach within the broad field of welfare services is considered to be a pertinent strategy to tackle wicked issues (Lister 2003; Frost 2005). This development is generally perceived as a sustainable solution to the persistence of the historical fragmentation of welfare services (Allen 2003; Provan \& Sebastian 1998). As Frost (2005: 11) asserts aptly, a highly specialized division of labor allows professionals to become "more specialist and more expert in their narrow fields". This has led to the creation of separate and categorical policy domains or areas (e.g. housing, welfare, employment, child services) in the provision of welfare services to citizens (Statham 2011) and to fragmented problem-solving mechanisms and procedures (Hood 2014). This fragmentation implies that welfare recipients, and especially those citizens who experience problems that are very complex and multi-dimensional in nature, encounter substantial obstacles or thresholds at the supply side of welfare provision, which prevents them from making use of, and benefiting from, the social resources and support provided by high-quality welfare services (Author's own 2016c). To avoid that citizens fall through the cracks of welfare provision (Allen 2003) and to realize a collaborative advantage that could not have been achieved by individual welfare actors and services alone, inter-organizational 
networking is therefore expected to tackle gaps and overlaps in the provision of welfare services while taking into account the complex and wicked problems of citizens (Rose 2011; Allen 2003; Vangen and Huxham 2013).

The central aim of this article is to explore the debates about normative value orientations within interorganizational networks that aim to combat child poverty. In Belgium, policy makers adopted an interorganizational networking approach as a relevant strategy to combat child poverty in social service delivery being organized at local governmental levels (Author's own 2016a, 2016c; Raeymaeckers and Dierckx 2012). Since current research on inter-organizational networking has often been conceived from a rather technical or managerial perspective (Provan and Milward 2001; Allen 2003; Frost 2005; Thompson and Perry 2006), our research question is formulated as follows: what are the varying strategies that are deployed by inter-organizational networks in dealing with normative value orientations when collectively tackling a wicked issue such as child poverty?

In the theoretical part, we first explore different fields of tension in the normative debates that might emerge when a wicked issue of child poverty is tackled. The concept of (child) poverty is not a neutral, but rather a normative and ideological construct, differing according to the ways in which it is defined and constructed by different actors in different societies (Lister 2004). The development of poverty and antipoverty strategies therefore often entails many different, and often contradictory, meanings and perspectives for different people, especially in the case of child poverty (Couture 2007). After having outlined our research methodology, we present our empirical findings about the different strategies that are developed within these local inter-organizational networks to deal with the fields of tension in normative debates about tackling child poverty. Finally, we make some general reflections about the role of inter-organizational networks as a means to (re-) organize social service delivery and to challenge dominant conceptualizations, definitions and strategies with regard to child poverty. Hence, although research shows that these perspectives also emerge in traditional welfare organizations (see Maeseele, 
2012), our empirical contribution reveals how inter-organizational networking and collaboration between welfare services intensifies the tensions and the debates about these issues. In this vein, we conclude that networks can function as valuable forums for collective debate and reflection, since different approaches and perspectives to tackle the problem of (child) poverty can be confronted with each other. Rather than avoiding discussion and debate, we argue that such a forum has the potential to challenge dominant conceptualizations and undesirable assumptions of complex social problems that are present in welfare discourses, policies and practices.

\section{Tackling child poverty: shifting normative value orientations in social work and welfare discourses}

\section{and practices}

An extensive body of international social policy and social work research shows that child poverty remains a stubborn, complex and multi-dimensional problem for social policy makers in most Western societies (Platt 2005; Lister 2006). Throughout history, Western welfare states have accordingly given great consideration to what causes harm to children in poverty situations, implying a priority given to social work to intervene in these situations (Parton 2011). In the context of the changing relationship between children, parents and the welfare state during the last century (Gillies 2008; Oelkers 2012), social work has evolved as a welfare practice with shifting normative value orientations. In that vein, Maeseele (2012) argues that a complex historical transition can be observed in social work from charity- to rights-oriented ideas and practices, that also reveals elements of continuity and discontinuity. Whereas charity-oriented social work practices paid an overwhelming attention to disciplining family life in order to protect children in poverty from their so-called 'irresponsible' parents (Lister 2003; Vanobbergen et al. 2006), rights-oriented practices consider the realisation of children's rights as always interrelated with a proactive realisation of the welfare rights of their parents (see Lister 2006; Schiettecat et al. 2014). Western welfare states have however recently developed a new concern about what causes harm to children, implying a renewed priority given to child and family social work for intervention in supposedly alarming situations, such as 
children living in poverty (Parton 2011). In that sense, recent research shows that the rights-oriented value orientation in welfare states has been particularly changing and shifting into charity-based ideas and value orientations, leading to the emergence of neo-philanthropic ideas and practices (Villadsen 2007; Maeseele 2012; Lorenz 2016; Krumer-Nevo 2016; Kessl, Oecher \& Schröder 2019).

Throughout these historical developments, scholars have argued that a new emphasis on the distinction between the 'deserving' and 'undeserving poor' manifests itself during the last decades (Villadsen 2007; Krumer-Nevo 2016; Garrett 2018). Our societies have long distinguished between the 'deserving' and 'undeserving poor' (Villadsen 2007), yet this currently results in a focal concern 'in the behaviour and attitudes of the poor and the 'competence' which should be expected of them' (Garrett 2018: 392). This is also at stake in the case of child poverty (Couture 2007). Although addressing child poverty is perceived as intrinsically legitimate, Goldson (2002) argues that the structural conditions in which children live expressions of poverty and inequality that are also experienced by parents - are substituted with a conceptual emphasis on individual responsibility. As such, a well-established conceptual schism has been resurrected in the form of the 'deserving' troubled child and the 'undeserving' troublesome' parents, who do not behave according to the norm of 'responsible' parenting (Goldson 2002).

\section{Features of charity- and rights-oriented approaches to social work}

In that vein, we rely on a conceptual frame of reference that has been developed by Maeseele (2012), which identifies three interrelated central fields of tension that indicate the features of, and distinction between, charity- and rights-based social work orientations in social policy and social work practice: whereas selectivity, conditionality and instrumental approaches refer to ideas being rooted in charityoriented welfare discourse and social work practice, universality, unconditionality and lifeworld-oriented approaches refer to rights-oriented value orientations in welfare discourse and social work practice (Villadsen 2007; Maeseele 2012; Morvaridi 2016). 
(1) Selective versus universal: Selectivity refers to the creation of criteria that determine whether welfare recipients have the right to a certain welfare state intervention, and entails a categorization (division) between those who deserve this and those who do not meet specific conditions that give access to social service provision as undeserving citizens (Villadsen 2007; Maeseele 2012). A universal approach implies that all citizens have the right to make use of support that is provided (Villadsen 2007; Maeseele 2012). In that vein, selectivity refers to the construction of target groups, and aims to direct public resources towards the most disadvantaged to maximize equality on the condition that they are willing to accept the social norm (Martin 2010). However in the implementation of these policy rationales, selective approaches often have stigmatizing effects (Maeseele 2012).

(2) Conditional versus unconditional: Judging this willingness to behave according to the social norm is rooted in the idea of 'goodwill' (Maeseele 2012). The component of goodwill refers to the dependence of the poor on those providing help and the goodwill of those providing help to assist those 'deserving' it (Payne 2005; Leighninger 2008). In social work, welfare conditionality refers to the fact that access to publicly provided welfare benefits and services is dependent on individual citizens first agreeing to meet particular obligations or patterns of behavior (see Dwyer 2004; Fletcher \& Flint 2018). People's access to welfare resources is restricted due to conditions that are implemented to change people's behavior. In that sense, the argument goes that people do not have rights without fulfilling their responsibilities. An unconditional approach implies that all citizens have the unconditional right to make use of support that is provided, without conditions or goodwill (Martin 2010; Brady and Burroway 2012).

(3) Instrumental versus life world-oriented: An instrumental social work practice means that the aim of what is to be done is defined from an external viewpoint and without taking into account what is considered as meaningful for welfare recipients (Maeseele 2012). This entails that the outcomes of the interventions are defined beforehand by the social workers, without consulting the welfare recipients about their 
definition of problems and solutions (Roose et al. 2013). Life world oriented principles and practices, on the other hand, take into account the aspirations, life worlds, and concerns of people in poverty situations (Grunwald and Thiersch 2009). This implies that social workers focus on the complex and dynamic relationship between the individual and society. According to a social justice orientation, the interplay between lifeworld and system becomes vital as they analyse how the everyday life is contingent on social and systemic forces (Grunwald and Thiersch 2009; Roets, Roose \& De Bie 2013).

Although the identified fields of tension are closely related and partly overlapping, there is however a subtle though important difference between them. It is important to note that the framework itself (developed by Maeseele 2012) should be perceived as a heuristic strategy to investigate the underlying and often shifting and changing normative assumptions in social work practice (see Schiettecat et al. 2018) rather than as an absolute typology that is often used in social policy scholarship (see Lister 2004; Dean 2015 for fruitful examples). As such, the heuristic framework also allows scholars to identity not only the normative principles and ambitions of (local) social policy but also how these principles are implemented and might shift and change while evolving in dynamic ways in social work practice (see Schiettecat et al. 2018). For example, selective and universal approaches mainly deal with the question whether (local) social policy makers and welfare actors construct target groups whereas conditional and unconditional approaches are basically about the actual and 'good' behavior social work practitioners expect. Moreover the differentiation allows us to make clear that it is possible, for example, that social work and welfare actors approach welfare recipients in selective (with reference to the rather exclusive focus on families in poverty) and instrumental (with reference to their rights and concerns not are taken into account from a social justice orientation) yet unconditional (with reference to having no further expectations about 'good' behavior or restrictions with regard to access imposed to these people) ways when dealing with wicked issues. A topical example involves the practice of food banks: they are often constructed as selective and instrumental initiatives for the poor yet unconditional in their implementation. 


\section{Research methodology}

\section{Research approach}

Being inspired by the heuristic framework, we explored the varying strategies of inter-organizational networks in dealing with normative value orientations in how to tackle child poverty in different municipalities in Belgium. The multiple case study was qualitative and ethnographic rather than comparative in nature (Spradley 1980). We therefore selected the cases in the different municipalities while embracing diversity in the cases (see table 1), and adopted a qualitative research approach to gain an in-depth and dynamic understanding of the meaning of the normative debates and the strategies being developed (Denzin \& Lincoln, 2003).

\section{Selection of the inter-organizational networks}

The research project was funded by a federal research foundation in Belgium. Despite the relative differences in social policy in the regions and the communities, the main focus of the project was therefore to examine the role of social welfare actors in the development of local inter-organizational networks being supported by federal social policy measures. In Belgium, the common orientation on the federal social policy level entails a rights-oriented approach due to a law of 1976 that is installed to guarantee the unconditional and universal right to human dignity that should be brought into practice in life world-oriented ways by professional social workers employed in Public Centres for Social Welfare, being constructed in each municipality in Belgium (see article 1, OCMW-law 1976). In the research project, we therefore developed the following inclusion criteria:

- The Public Centre of Social Welfare (OCMW), being constituted on the federal Belgian level for social work to pursue the unconditional right to human dignity, had to be one of the partners in the network.

- The network and its organizations must have worked with families with children in poverty, but not exclusively. 
- The network had to consist of autonomous organizations that were different but with complementary functions, rather than an integration of these different functions in one single organization.

- The child poverty rate per municipality or community had to be higher than the average rate.

In addition to the inclusion criteria, we wanted to create a diverse sample of networks. Therefore, the following diversity criteria were also determined: network location (urban and rural), size, history of working together, sectoral diversity. Additionally, we took into account the willingness of local network actors to collaborate in this study (being open to participative observation and interviews) and considered interesting practices that were developed in the network.

We provide an overview of all the diverse characteristics of the selected networks in table 1.

\section{Table 1: network characteristics/diversity criteria}

The four selected networks are funded either by the regional or by the national governmental department responsible for poverty reduction. Networks $A$ and $B$ are located in Flanders, the Dutch-speaking part of Belgium. Network $A$ is situated in a suburban municipality. This network consists of five partners that together combine the provision of material and immaterial support (e.g. welfare allowances, employment, parent support). It is targeted towards vulnerable families with a child initially between 0 and 3 years old, and aimed at developing individualized support trajectories for a maximum of three years, coordinated by a case coordinator. The trajectories start by examining with the parents whether all the rights/benefits they are entitled to are realised on many different life domains (for example housing, employment, leisure time, education, income and mobility).

Network B is located in a small municipality in a rural region in Flanders, and involves in total over 60 individual members. This network aims to provide parent support for all families with children in the community. The network deals with complex social problems, including high numbers of ethnic minorities, 
high unemployment, low average income, high residential density, and so on. The network consists of many network partners (at the start 60 individual members) from sectors such as education, (preventive) parenting support, leisure time, health care and welfare. By creating a "House of the Child", the network aims to provide a physical meeting place and contact point for families with children in the municipality. Network interventions such as play and meeting moments for parents and children, information moments, consultations, and trajectories for pregnant woman are offered to all families in the municipality.

Networks $C$ and $D$ are located in Wallonia, the French-speaking region in Belgium. Network $C$ aims to provide childcare and parenting support for all families with children under three years old, with special attention being paid to the creation of affordable and accessible services for families in poverty in 15 rural communities. Network $\mathrm{C}$ develops and supports day-care for children, especially for children in poverty situations whose parents are involved in welfare-to-work programs. Besides, the network provides parenting support through educational and cultural activities and workshops.

Network D is located in Wallonia targets children and teenagers, and aims to prevent early school leaving and bullying. It starts from a street-level approach to reduce the distance between service providers and users where the school is seen as a very important actor in the network. Network D brings together 30 services from various domains, such as youth, education, welfare and poverty. The coordinator and the partners focus on problems such as bullying, harassment, early school leaving and early parenthood, and want to develop a joined-up approach to decrease service fragmentation and offers comprehensive support for teenagers.

\section{Data collection strategies}

In order to investigate these networks, two qualitative research methods for data collection were combined: participant observation during the network meetings and activities; and qualitative interviews with actors of the network. Two researchers (first and second author) were involved in the relevant settings 
and activities of the networks (Nandhakumar and Jones 1997). Participant observation served as an appropriate research method to offer thick descriptions of field experiences (Patton 2002; Denzin and Lincoln 2003). The observations took place during meetings of the network actors (10 in network $A, 13$ in network $C, 15$ in network $C$, and 11 in network D). Documenting the discussions in detailed and contextualized ways during these meetings provided an in-depth insight into the actual meaning, implementation, and value orientation of the networks. The participant observation was spread over a period of two years. The frequency of the observations was dependent on the frequency of the meetings of the networks. Each of these meetings took between two and three hours. None of the meetings or informal discussions were audio-recorded, but field notes were taken. For participant observation, is it important to separate observation from interpretation when taking notes (Mack et al. 2005). In so doing, the participant observation provides a context that allows us to understand the data that are collected through other methods (Mack et al. 2005).

In addition, we conducted semi-structured interviews with central local network actors, to take into account the actors' perspective (Patton 2002: 341). The selection of the network actors was based on the condition that they fulfill a significant role on the strategic level in shaping and steering the networks and their interventions. Eventually, 19 qualitative interviews were conducted with the network coordinators (4 in network 1, 4 in network B, 5 in network C, and 6 in network D) and 37 interviews were conducted with the social workers involved (8 in network A, 7 in network B, 15 in network $C$, and 7 in network D). Topics concerning the role of local social policies and strategies on (child) poverty reduction and networking between organizations and sectors were discussed. The research was approved by the ethical committee of the university and informed consents were systematically obtained.

Strategies of data analysis 
We analyzed the data (field notes and interviews) through a qualitative content analysis. Hsieh and Shannon (2005: 1278) define this as 'a research method for the subjective interpretation of the content of text data through the systemic classification process of coding and identifying themes or patterns'. It is used as a sense-making effort that attempts to systematically analyze and identify core consistencies and meanings in qualitative research material (Patton 2002; Kohlbacher 2006). In our analysis, we were relying on the three existing fields of tension in the literature that allowed us to capture the rationales, strategies and actions that are directed towards families and children, and to illustrate complex debates for local welfare actors. Since the creation of inter-organisational networks between a wide range of welfare services for children and families might produce similar challenges, our analysis focuses on these three fields of tensions. These fields of tension influence the rationales, strategies and actions that are directed towards families and children, but we revised them to do justice to the discussions and dynamics that evolved in and across networks to create shared strategies in dealing with child poverty: (1) selective versus universal provision; (2) child- versus family-oriented strategies, and (3) instrumental versus lifeworld oriented approaches. As such, a directed approach to qualitative content analysis (Hsieh and Shannon 2005; Myring 2000) was applied. This process of data analysis, in which we persistently triangulated different data sources (observations and qualitative interviews), allowed us to validate and cross-check our research findings. The validity and reliability of our research findings was also established through the prolonged engagement of the researchers, peer debriefing, and careful consideration in our research team (Morse et al. 2002).

\section{Research findings}

\section{Universal versus selective provision}

This field of tension deals with the discussion about the target group and the question whether the network should serve welfare recipients in universal or selective ways. In the different networks, we observed how the network actors try to connect both poles of selective or universal principles and practices. Our cases 
show that both approaches are used for different strategies and goals that evolve in dynamic ways over time.

For example, Network A starts from a selective approach by targeting families in poverty. Individual trajectories are constructed to support families in poverty in a multidimensional way and using a rights based orientation. Nevertheless, this trajectory is only possible for a limited number of families (in this case 40), which raises questions about the accessibility of the network. Still, it is effective in reaching poor families and realizing their rights on many different life domains. The network tries to compensate its selective character by developing a strategy to broaden this selective approach into a more universal approach. The signals and problems that were discovered by implementing the individual support trajectories, were also discussed and dealt with on a broader local policy level. In this way, other families of the local community (who are not directly included in the network's support and activities) may also benefit from the network. For example, the lack of affordable and qualitative housing was presented to a local council where local housing policies were developed to tackle this problem. The impact of the network, therefore, goes beyond the selective approach where every citizen can potentially benefit from the network activities.

Other examples could be observed in Networks B and C. These networks started from a universal approach, that was initially used as a strategy to include vulnerable parents in the network. Network C's objective was to promote accessibility and affordability for poor families in a newly created childcare facility. Even though this was formulated as an aim, the network members stated that they faced difficulties in reaching these poor families and this was perceived as deeply problematic. In this network, a partner suggested developing a new strategy to overcome this problem, namely using a selective approach instead of a universal approach to fulfill the objectives of the network. Another partner also reflected on this and mentioned that in some ways, inequalities in the child care system are reproduced, due to the fact that the network doesn't reach families in poverty as supposed to. This partner therefore seems to suggest that processes of social exclusion are reproduced by the network that aims to combat child 
poverty. To prevent the exclusion of vulnerable families, the network decided to create an income-related system in their childcare facility to increase the affordability of their services and decrease the threshold for poor families. As they argue, "we have to make sure that stronger families don't oppress the vulnerable ones" (own translation). The network still defends a universal approach as they aim to serve a socially diverse group and avoid stigmatization.

Network B started from a universalist approach, by creating a 'House of the Child' as a low-threshold provision and contact point for all families with children in the community. Still, the network struggled to reach vulnerable parents, and the network coordinator made this repeatedly explicit during the network meetings. During this meeting, it became clear that the inequality of use was not only seen as a problem of non-participation, but also as an issue of spending the financial means of the network. A partner of the network defended a more selective approach to tackle child poverty and challenged this universalist approach. This person contested: "Are the funds that are acquired for combating poverty actually used for this group in particular? Or do all the resources and benefits go to families who do not live in poverty?" (own translation). This discussion was also raised in another network meeting, and the principle of proportionality was mentioned to defend the idea that the budget should benefit the well-being of families in poverty more than the wellbeing of more affluent families. In reaction, the coordinator of the network stated that: "It should not become a House of the "problem" Child instead of a House of the Child", to underpin the argument that a selective and targeted approach would create a stigmatizing label. The selective approach might paradoxically produce an inaccessibility for all families, and more particularly might scare families in poverty.

\section{Conditional versus unconditional strategies}

Families in poverty situations are often confronted with a complex web of material and non-material problems which cut across a wide range of policy domains and service areas (Lister 2004; Clarke and Stewart 1997; Main 2014). The wellbeing of the child was the starting point of these networks who aim to 
combat child poverty, and therefore this viewpoint entails the risk of implementing conditional social work practices towards parents who risk to be constructed as citizens who are deserving of support and resources only for the sake of their children. Although child-centered interventions seem to construct the child a the main reason for intervention in several practices, other practices challenge this subtle conditionality towards parents and were developed within and across the networks in relation to the family as a whole.

In some of our interviews with central local network actors (Networks A and B), a social investment paradigm was present in (child) poverty reduction strategies. Children, in this vein, were considered as potentially worthwhile and beneficial social investments. This was argued in Network A because of the higher potential of breaking the cycle of poverty if the interventions were targeted towards young children. The problem was framed as a problem of inequality and consequently the interventions were aimed at closing the gap between the rich and the poor at a young age, to prevent children from falling behind in school and in participation in leisure time activities. The coordinator of this network stated that this may have a bigger return to society and that children will get more experiences to build on. So in Network A, having a child aged between 0 and 3 years old was an explicit condition of being included in the support that was provided by the network. Although this policy choice directly targets children, the actions taken by the network partners affected the well-being of all family members, because structural dimensions like housing, employment, social support, financial support, etc., impacted on the family as a whole. In the interviews, local policy makers from Network A made it clear that it was crucial to include the context of the child to combat child poverty, because children who grow up in a family in poverty experience fewer chances and increased exclusion in multiple life domains. In Network B, a focus on talent development appeared to be one of the drivers to invest in children. One of the policy makers explained that it was a matter of following the political and scientific discourse in his choice to target young children and even claimed that targeting, for example, a 14-year-old would not make a difference in the effort to break the 
cycle of poverty. In this way, the needs of older children and also of parents were not taken into account, and so they risked exclusion from the network's focus.

The focus on children may equally well be used as a strategy to include all family members. Some of the network actors in Networks A and B, for example, argued during the interviews that it is less stigmatizing if the well-being of the child serves as a starting point for interventions. They argue that parents don't have to feel approached because they are poor, but because they are a parent. A local welfare actor of Network B stated that when the wellbeing of the child is central to the intervention, this makes other family members more willing to cooperate with services. So the child oriented strategy was used to achieve a family oriented strategy.

In Network C, a change in staff occurred and, as a consequence, the support offered also changed over time. The original aim of the network was to provide a multi-dimensional and family approach, including childcare performed by pediatric nurses and parent support performed by social workers. After a while, the team evolved and consisted predominantly of pediatric nurses instead of social workers. As a consequence, the network gradually focused more on childcare than on parent support. During the participant observation, it was clear that even though they received questions from parents that deal with very complex and difficult situations, the network became more child-oriented.

\section{Instrumental versus life world-oriented approaches}

In order to develop high quality provision for families by dealing with fragmentation and sectoral segregation (Author's own 2013), some network members argue that the well-being and concerns of parents and children in poverty situations need to be considered as multidimensional, with reference to providing material as well as immaterial support including issues of health, housing, employment, and education (Lister 2004; Allen 2003; Broadhead et al. 2008). The networks in our study made different choices in providing resources to parents and children: some were taking into account the life worlds and 
concerns of both parents and children, whereas others developed welfare services in more instrumental ways.

In that vein, the networks in our study made different choices in providing support to parents and children. Network A started their actions from the aspirations, life worlds and concerns of families in poverty situations. Network B and D for example, developed welfare services in more instrumental ways and actions and outcomes were defined beforehand by social workers, without consulting the families about how they would define and construct it.

Network A, for example, organizes individual support trajectories where the needs of each individual family served as the starting point of the interventions. The support was based on the dialogue and negotiation about the questions and needs of the family. Consequently, on many occasions material as well as immaterial resources were provided, and many different life domains were covered, acknowledging the multidimensionality and complexity of the problems of trying to realize welfare rights on several life domains, including housing, childcare, employment, and allowances.

Another example manifests itself in Network B, which aimed to be a new gateway for families in relaying questions from parents to social work organizations. Additional attention was paid to the inclusion of poor families in newly developed parent support initiatives. Yet, defining the needs of families in instrumental ways (i.e., their need for parent support) may have contributed to their exclusion, as Network B faced difficulties in reaching poor families. During a network meeting, the coordinator told the partners that she received 33 questions, mostly from parents who don't live in poverty, that were mainly educational and relational in nature. One could wonder if the instrumental definition of concerns (as primarily educational) created this problem, in cases when poor families did not consider their problem as educational or relational, but as material in nature. Structural dimensions of combating poverty, like housing and employment, were not included domains of action in Network B. 
Network D started from a street corner work approach to reach vulnerable citizens. The importance of outreach was stressed by the partners and coordinator as "it helps our provision to understand the needs of our potential users" (own translation). Even though this was the explicit starting point of the network, according to the coordinator the strategy changed due to financial reasons from a life world oriented approach to having an externally defined and specific mission, life domain, and target group. At present, the interventions are mainly situated in domains of youth and school (to prevent early school leaving and bullying). This resulted in the fact that some of the network partners did not and could not fully commit anymore to deal with other life domains, even when these issues seemed to be vital for the families involved. One partner formulated this as follows: "If we don't start over the whole process, we cannot be sure that we are not excluding some families according to the fact that we do not engage in a more indepth analysis of what is at stake" (own translation). The switch to a focus on youth and school also led to a disengagement of partners who did not work in these specific fields, as they were aware that this evolution would exclude people.

\section{Concluding reflections}

In this article, we explored the debates about normative value orientations of inter-organizational networks amongst a wide variety of welfare actors who collectively aim to tackle a wicked issue such as child poverty. Our study was informed by a heuristic framework (see Maeseele 2012) to investigate the underlying and often shifting and changing normative assumptions in social work practice, to identity not only the normative principles and ambitions of (local) social policy but also to gain knowledge of how these principles are implemented and might shift and change while evolving in dynamic ways in social work practice (see Schiettecat et al., 2018). Based on the conceptual difference between charity- and rightsoriented social work practices that are captured in three fields of tension, our results show a diversity of normative value orientations and divergence in the operational and strategic choices that were made 
within the networks under study. Hence, although the four local networks shared an overall goal and purpose - i.e., combating (child) poverty and making connection with the federal law on securing the right to human dignity (according to the CPAS/OCMW-law of 1976) - we observed major differences in the strategies that were developed. In our view, this relates to the recognition that these tensions about how to tackle wicked issues could not, and should not, be 'solved' through inter-organizational networks.

Hence, rather than considering the creation of these networks as a goal in itself, we consider them as additional instruments for local policy makers and welfare organizations to remain engaged in a constant process to give meaning to these tensions. The findings clearly show how the search for a shared vision and the collective development of concrete operational practices gives rise to disagreement and sometimes even conflict. One recurrent driver for discussion related to the fact that network partners became aware that their strategies simultaneously seemed to include some families yet exclude others, especially with reference to the question of whether the network activities contributed to the realization of the rights of families in poverty situations (see Hughes and Mac Naughton 2000). Embracing democratic disagreement might therefore be advantageous as Lubeck (1998: 290) asserts:

'Finding comfort in consensus, may make us too sure that what we know is best for ourselves is also best for others. Uncertainty, by contrast, is unsettling, it makes us wonder, listen and try new things. It opens up the possibility that things can be other than they seem'.

In this vein, it is not surprisingly that we observed that network goals and strategies were regularly challenged, renegotiated, and thus evolved in organic and democratic ways over time. More importantly, however, our study shows that an openness for collective debate and reflection could also challenge dominant assumptions and self-evident problem definitions of strategies to deal with child poverty and is therefore desirable (Author's own 2016c). Our research indicates, for example, that the involvement of the Public Centres for Social Welfare as key actors in the development of networks to combat child poverty 
in Belgium might therefore be crucial, since they have the formal and public mandate to realize the right to human dignity in Belgium for all citizens in universal, unconditional, and life world-oriented ways. Due to the way local networks are funded in Belgium, the Public Centres for Social Welfare are encouraged to become the leading applicant and are therefore often one of the leading organizations in the network. Also, the Public Centre for Social Welfare is present in every municipality and is the most established welfare organization on the local level. In a context of combating (child) poverty, it is important to take into account this network partner, who also provides material support to the local community. However there are also differences in how the Public Centres for Social Welfare are positioned in the Dutch and French speaking regions in Belgium (for example, in Flanders they are perceived as key managers and leaders in local social policy), and in how they consider and shape their own role in the networks (see Span \& al. 2012)1. We therefore argue that combating child poverty requires networks - and actors who can take leading roles in shaping the network activities - which operate as platforms for collective debate and reflection in the development of a common rights-oriented rather than charity-based normative value orientation over time; yet this crucially requires that democratic disagreement and even conflict are embraced and fostered. These processes of reflection, which occur both within and across organizations that constitute a network, are vital and meaningful as they serve as levers to incorporate the needs, concerns and meaning-making of the families and children who might benefit from the network activities (Grunwald and Thiersch 2009; Author's own 2016c). Author's own (2016b: 8) argued that this pursuit of a potential surplus value for welfare recipients 'reveals an important question about the normative frame of reference, that guides network actors when they collaborate'. Rather than protecting children in poverty as supposed 'victims' of the so-called 'bad' education of parents, we argue that poor children are always children of poor parents (Mestrum 2011). In that sense, we argue that combating the wicked issue of child poverty can only be significant when it is embedded in a rights-oriented approach (McKeown et al. 2014;

\footnotetext{
${ }^{1}$ Span et al. (2012) developed a framework of three different governance roles that can be placed on a top-down - bottomup continuum: the commissioner, the co-producer and the facilitator.
} 
Anthony et al. 2011; Smith et al. 2008), in which the realisation of children's rights is always interrelated with a proactive realisation of the welfare rights of their parents (see Lister 2006; Schiettecat et al. 2014).

\section{References}

Author's own (2013)

Author's own (2016a)

Author's own (2016b)

Author's own (2016c)

Alford, J. and Head, B.W. (2017), Wicked and less wicked problems: a typology and a contingency framework, Policy and Society, 36, 3: 397-413.

Allen, C. (2003), Desperately seeking fusion: on "joined-up thinking", "holistic practice" and the new economy of welfare professional power, British Journal of Social Work, 54, 2: 287-306.

Anthony, E., King, B. and Austin, M. (2011), Reducing child poverty by promoting child well-being: Identifying best practices in a time of great need, Children and Youth Services Review, 33, 1999-2009.

Brady, D. and Burroway, R. (2012), Targeting, universalism, and single-mother poverty: a multilevel analysis across 18 affluent democracies, Demography, 49, 719-746.

Broadhead, P., Meleady, C. and Delgado, M. (2008), Children, Families and Communities: Creating and Sustaining Integrated Services, United Kingdom: Open University Press.

Clarke, M. and Stewart, J. (1997), Handling the Wicked Issues: A Challenge for Government, Birmingham: University of Birmingham, Institute of Local Government Studies.

Couture, P. (2007), Child poverty: love, justice, and social responsibility. St. Louis: Chalice Press. 
Denzin, N.K. and Lincoln, Y.S. (2003), Collecting and Interpreting Qualitative Materials, Thousand Oaks California: Sage.

Devaney, J. and Spratt, T. (2009), Child abuse as a complex and wicked problem: Reflecting on policy developments in the United Kingdom in working with children and families with multiple problems, Children and Youth Services Review, 31, 6: 635-641.

Dwyer, P. (2004), Creeping conditionality in the UK: from welfare rights to conditional entitlements?, The Canadian Journal of Sociology, 29, 2: 265-289.

Ferlie, E., Fitzgerald, L., McGivern, G., Dopson, S. and Bennett, C. (2011), Public policy networks and wicked problems: A nascent solution? Public Administration, 89, 2: 307-324.

Frost N. (2005), Research in Practice: Professionalism, Partnership and Joined-Up Thinking: A Research Review of Front-Line Working with Children and Families, Totnes: Devon.

Fletcher, D.R. and Flint, J. (2018, published online), Welfare conditionality and social marginality: the folly of the tutelary state?, Critical Social Policy, https://doi.org/10.1177\%2F0261018317753088

Garrett, P.M. (2018), Welfare words: critical social work and social policy. London: Sage.

Gillies, V. (2008), Perspectives on parenting responsibility: Contextualizing values and practices, Journal of Law and Society, 35, 1: 95-112.

Goldson, B. (2002), New Labour, Social Justice, and Children: Political calculation and the deservingundeserving schism, British Journal of Social Work, 32, 6: 683-695.

Grunwald, K. and Thiersch, H. (2009), The concept of the 'lifeworld orientation' for social work and social care, Journal of Social Work Practice, 23, 2: 131-146. Doi: 10.1080/02650530902923643

Hood, R. (2014), Complexity and integrated working in children's services, British Journal of Social Work, 44, 27-43. Doi: 10.1093/bjsw/bcs091 
Hsieh, H.F. and Shannon, S.E. (2005), Three approaches to qualitative content analysis, Qualitative Health Research, 15, 9: 1277-1288. Doi: 10.1177/1049732305276687

Hughes, P. and MacNaughton, G. (2000), Consensus, dissensus or community: the politics of parental involvement in early childcare education. Contemporary Issues in Early Childhood, 1, 3: 241-258.

Huxham, C. (2003), Theorizing collaborative practice, Public Management Review, 5, 3: 401-423.

Keast, R., Mandell, M.P., Brown, K. and Woolcock, G. (2004), Network structures: working differently and changing expectations, Public Administration Review, 64, 3: 363-371.

Span, K. C. L., Luijkx, K. G., Schols, J. M. G. A. and Schalk, R. (2012). The Relationship Between Governance Roles and Performance in Local Public Interorganizational Networks: A Conceptual Analysis. The American Review of Public Administration, 42: 186.

Kessl, F., Oechler, M., and Schroeder, T (2016/in press), Charity Economy. In: Kessl Fabian, Walter Lorenz, Hans-Uwe Otto, Sue White (Eds.): European Social Work - A Compendium. Leverkusen \& Farmington Hills: Barbara Budrich Publisher.

Kohlbacher, F. (2006), The use of qualitative content analysis in case study research, Forum: Qualitative Social Research, 7, 1: Art. 21.

Krumer-Nevo, M. (2016), Poverty-Aware Social Work: A Paradigm for Social Work Practice with People in Poverty, British Journal of Social Work, Advance Access https/doi.org/10.1093/bjsw/bcv118

Leighninger, L. (2008). The history of social work and social welfare. In K.M. Sowers \& C.N. Dulmus (Eds.), Comprehensive handbook of social work and social welfare. The profession of social work. (pp. 1-24) Hoboken/New Jersey: John Wiley \& Sons Inc.

Lister, R. (2003), Investing in citizen-workers of the future: transformations in citizenship and the state under New Labour, Social Policy \& Administration, 37: 427-443.

Lister, R. (2004), Poverty, Cambridge: Polity Press. 
Lister, R. (2006), Children (but not women) first: Now Labour, child welfare and gender, Critical Social Policy, 26, 5: 315-335

Lorenz, W. (2016), Rediscovering the social question, European Journal of Social Work, 19:1, 4-17, DOI: $10.1080 / 13691457.2015 .1082984$

Lubeck, S. (1998), Is developmentally appropriate practice for everyone? Childhood Education, 74, 5: 283-292.

Mack, N., Woodsong, C., MacQueen, K., Guest, G. and Namey, E. (2005), Qualitative Research Methods: A Data Collector's Field Guide, North Carolina: Family Health International.

Maeseele, T. (2012), From charity to welfare rights? A study of social care in practices. PhD thesis, Ghent University. Retrieved from http://hdl.handle.net/1854/LU-3066986

Martin, C. (2010), The reframing of family policies in France: processes and actors, Journal of European Social Policy, 20, 5: 410-421.

McKeown, K., Haase, T. and Pratschke, J. (2014), Evaluation of national early years access initiative \& Siolta quality assurance programme: A study of child outcomes in pre-school. Ireland

Mestrum, F. (2011). Child poverty. A critical perspective, Social Work \& Society, 9, 161-168.

Morse, J.M., Barrett, M., Mayan, M., Olson, K. and Spiers, J. (2002), Verification strategies for establishing reliability and validity in qualitative research, International Journal of Qualitative Methods, 1, 2: 1-19.

Morvaridi, B. (2016). New philanthropy and social justice: debating the conceptual and policy discourse. Bristol: Policy Press.

Myring, P. (2000), Qualitative content analysis, Forum: Qualitative Social Research, 1, 2: 1-10.

Nandhakumar, J. and Jones, M. (1997), Too close for comfort? Distance and engagement in interpretive information system research, Information Systems Journal, 7, 109-131. 
Oelkers, N. (2012). The redistribution of responsibility between state and parents: Family in the context of post-welfare-state transformation. In M. Richter \& S. Andresen (Eds.), The Politicization of Parenthood (pp. 101-110). London, UK: Springer.

Patton, M.Q. (2002), Qualitative Research and Evaluation Methods - 3rd edition. Thousand Oaks: Sage Publications.

Parton, N. (2011), Child protection and safeguarding in England: Changing and competing conceptions of risk and their implications for social work, British Journal of Social Work, 41, 854-875.

Payne, M. (2005), The Origins of Social Work: Continuity and Change. Palgrave: Basingstoke.

Platt, L. (2005), Discovering child poverty: the creation of policy agenda from 1800 to the present. Bristol: The Policy Press.

Provan, K.G. and Sebastian, J.G. (1998), Networks within networks: service link overlap, organizational cliques, and network effectiveness, Academy of Management Journal, 41, 4: 453-463.

Raeymaeckers, P. (2010), Working together? Social integration and the effectiveness of networks among human service organizations, European Journal of Social Work, 13, 4: 561-566. doi: $10.1080 / 13691457.2010 .536380$

Rittel, H.W.J. and Webber, M. (1973), Dilemmas in general theory of planning, Policy Sciences, 4, 155169.

Roose, R., Roets, G., Van Houte, S., Vandenhole, W. and Reynaert, D. (2013), From parental engagement to the engagement of social work services: discussing reductionist and democratic forms of partnership with families, Child \& Family Social Work, 18, 4: 449-457.

Rose, J. (2011), Dilemmas of inter-professional collaboration: can they be resolved?, Children \& Society, 25, 2: 151-163. 
Schiettecat, T., Roets, G. and Vandenbroeck, M. (published online, 2016), What families in poverty consider supportive: welfare strategies of parents with young children in relation to (child and family) social work, Child \& Family Social Work.

Schiettecat, T., Roets, G. and Vandenbroeck, M. (2018), Hide and seek: political agency of social workers in supporting families living in poverty, British Journal of Social Work, 48, 7: 18741891.

Smith, P., Daniels, H., Edwards, A., Apostolov, A., Brown, S., Kinti, I. , Leadbetter, J., Martin, D., Martsin, M., Middleton, D., Parsons, S. G., Popava, A., Warmington, P., \& Youngs, S. (2008). Learning in and for multi-agency working in preventing social exclusion. Research Brief. London : Institute of Education.

Spradley, J.P. (1980), Participant Observation, New York: Holt, Rinehart, and Winston.

Statham, J. (2011), Working Together for Children. A Review of International Evidence on Interagency Working, To Inform the Development of Children's Services Committees in Ireland, London: Department of Children and Youth Affairs.

Thompson, A.M. and Perry J.L. (2006), Collaboration processes: inside the black box, Public Administration Review, 66, Special Issue: 20-32.

Vangen, S. and Huxham, C. (2013), Building and using the theory of collaborative advantage. In: R. Keast, M. Mandell, and R. Agranoff (eds), Network Theory in the Public Sector: Building New Theoretical Frameworks, New York: Taylor and Francis.

Vanobbergen, B., Vandenbroeck, M., Roose, R., Bouverne-De Bie, M., (2006), "We are one big, happy family": beyond negotiation and compulsory happiness, Educational Theory, 56, 4: 423-437.

Villadsen, K. (2007), The emergence of 'neo-philanthropy'. A new discursive space in welfare policy?, Acta Sociologica, 50, 3: 309-323. 
Villadsen, K. (2007), The emergence of « Neo-Philanthropy » : A New Discursive Space in Welfare Policy?, Acta Sociologica, 50, 9: 309-323.

Weber, E.P. and Khademian, A.M. (2008), Wicked Problems, Knowledge Challenges, and Collaborative Capacity Builders in Network Settings, Public Management Review, 68, 2: 334-349. 